Pure Appl. Chem., Vol. 82, No. 12, pp. 2231-2246, 2010.

doi:10.1351/PAC-CON-10-08-04

(C) 2010 IUPAC, Publication date (Web): 4 October 2010

\title{
Recent advances in the total synthesis of agelastatins*
}

\author{
Guangbin Dong \\ Division of Chemistry and Chemical Engineering, California Institute of Technology, \\ Pasadena, CA 91125, USA
}

\begin{abstract}
Agelastatins represent an important family of marine alkaloids in terms of both exceptional biological activity and intriguing chemical structure. In this article, the isolation and biological activity of agelastatins are reviewed, and proposed biosynthetic pathways are summarized. The main focus is given to comparative evaluation of recent total syntheses, mainly of agelastatin A. To date, this has been accomplished by 11 research groups. Their synthetic routes are analyzed and summarized, with a view to furnishing the reader with insight into different strategic design approaches to assembly of a densely functionalized and compact structure.
\end{abstract}

Keywords: anticancer activity; asymmetric synthesis; isolation; natural products; total synthesis.

\section{INTRODUCTION}

As treasure from the ocean, marine sponges constitute a rich source for medicinally important natural products. Among various structurally intriguing secondary metabolites, pyrrole-imidazole alkaloids represent an important class, which exhibits a vast range of biological properties [1]. This is exemplified by the agelastatins, which have remarkable anticancer activity. Given their significance, both in terms of biological activity and the challenge posed by their structural complexity, numerous synthetic approaches have been explored during the past decade. Although some of the earlier efforts have been covered in part of a review by Weinreb in 2007 [2], a tremendous amount of more recent synthetic investigation has been disclosed during the past four years, which has been additionally stimulated by more recent oncology studies during 2008 [3] and isolation of new agelastatins during 2010 [4]. For example, in 2009 alone, no less than six publications appeared on the total syntheses of agelastatin A. This article aims to outline a historical review on the isolation, biology, and synthesis of this fascinating family of natural products. Particular attention will be drawn to those strategies that highlight the dramatic impact of synthetic efficiency on overall results.

\section{ISOLATION AND BIOLOGICAL ACTIVITY}

Agelastatin A (1) was originally isolated by Pietra et al. in 1993 from the axinellid sponge Agelas dendromorpha collected in the Coral Sea near New Caledonia [5] (Fig. 1). A minor congener was isolated as agelastatin B (2) with an additional bromo substituent at C(14). Conformational preferences and the

*Pure Appl. Chem. 82, 2231-2314 (2010). A collection of invited, peer-reviewed articles by the winners of the 2010 IUPAC Prize for Young Chemists. 

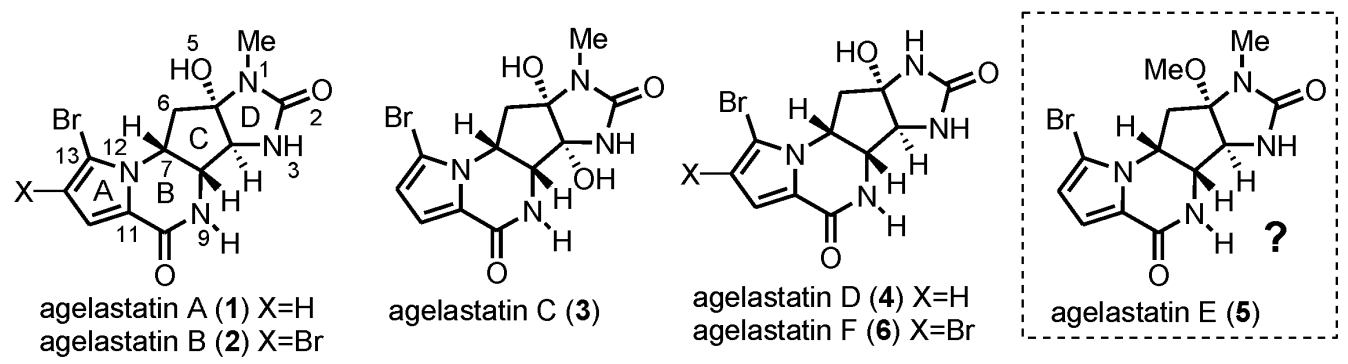

Fig. 1 Agelastatins.

absolute configuration of agelastatin A were determined by semisynthetic derivation, molecular modeling, and spectroscopic analysis [6,7]. In addition to structural verification arising from earlier total synthesis, the structure of $\mathbf{1}$ was unambiguously determined through X-ray crystallography of material isolated from Mexican Agela sp. by Pettit [8]. Agelastatins C (3) and D (4) were isolated from the West Australian sponge Cymbastela sp. by Molinski and co-workers in 1998 [9]. Agelastatin C contains an extra hydroxyl group at C(4); whereas agelastatin D lacks an N(1) methyl group. Very recently (2010), agelastatins $\mathrm{E}(\mathbf{5})$ and $\mathrm{F}(\mathbf{6})$ were isolated as minor components from a butan-1-ol extract of the New Caledonian sponge $A$. dendromorpha, along with agelastatin A [4]. Agelastatin E is formally $O$-methylagelastatin $\mathrm{A}$; while agelastatin $\mathrm{F}$ is 14-bromoagelastatin $\mathrm{D}$. The question whether agelastatin $\mathrm{E}$ is a natural product has not yet been addressed [4]. As indicated in Pietra's initial semi-synthesis work [6] (later confirmed by Movassaghi's seminal total synthesis [10]), treatment of $\mathbf{1}$ in the presence of Amberlyst 15 and $\mathrm{MeOH}$ results in methanol exchange at $\mathrm{C}(8)$, giving $O$-methylagelastatin $\mathrm{A}$, the ${ }^{1} \mathrm{H}$ NMR spectrum of which is identical to that of agelastatin $\mathrm{E}$ (eq. 1). Thus, there is a possibility that compound 5 was formed during the purification process.<smiles>CN1C(=O)N[C@H]2[C@H]3NC(=O)c4ccc(Br)n4[C@@H]3C[C@]2(O)[C@H]1C(C)(C)C</smiles>

agelastatin $A(1)$

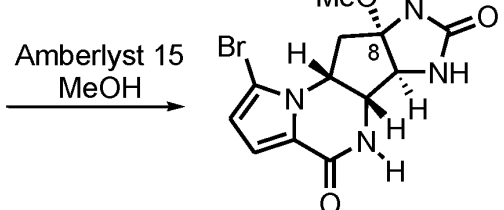

agelastatin $\mathrm{E}(\mathbf{5})$

Among various oroidin-family alkaloids that have been isolated, agelastatin A was the first to exhibit exceptional cytotoxicity toward a range of cancer cell lines, including human KB nasopharyngeal cancer cells $\left(\mathrm{IC}_{50}=0.075 \mu \mathrm{g} / \mathrm{ml}\right)$, L1210 murine tumor cell line, RT112/84 bladder carcinoma cells, SK-MEL-5 melanoma cells, HCT-116 colon carcinoma cells, and MDA-MB-435s breast cancer cells $[8,11]$. In many cases, agelastatin A was shown to be 1.5 to 16 times more potent than the frontline chemotherapeutic agent cisplatin, but with low toxicity [3]. Recent oncology studies by Hale and co-workers have shown that agelastatin A inhibits osteopontin-mediated adhesion, invasion, and colony formation, suggesting that it can serve as a potent anti-invasive agent [3]. Two mechanisms have been suggested for the antimetastatic activity of agelastatin A: (1) it blocks the Wnt signal pathway; (2) it can arrest cancer cells in the G2 phase of the cell cycle.

Agelastatin A also exhibits a number of other important activities. For example, it selectively

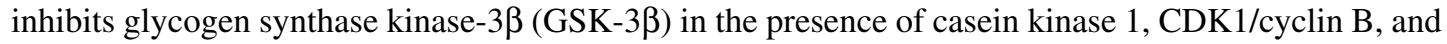
$\mathrm{CDK} 5 / \mathrm{p} 25$ at low concentration $\left(\mathrm{IC}_{50}=12 \mu \mathrm{M}\right)$, suggesting a potential approach for the treatment of Alzheimer's disease [11]. Hale et al. have suggested that agelastatin A might also function as a novel 
insulin mimetic [13]. In addition, agelastatin $\mathrm{A}$ has been reported to possess potent activity against brine shrimp $\left(\mathrm{LC}_{50}=1.7 \mathrm{ppm}\right)$, larvae of beet armyworm, and corn rootworm [9].

Structure-activity relationship (SAR) studies indicate that 5-OH, 3-NH, and 9-NH functionality is essential for the cytotoxicity of agelastatin A [7], since alkylation or acylation of any of these sites leads to significant loss of activity. The 13-bromo group is also considered to be important for optimal activity because its absence results in an increase of $\mathrm{IC}_{50}$ value against $\mathrm{L} 1210$ cells from 0.033 to $0.143 \mu \mathrm{g} / \mathrm{ml}$. It is noteworthy that other naturally occurred agelastatins B-F show dramatically diminished biological activity by comparison with agelastatin A (1), indicating that the unique pattern of functionality in agelastatin $\mathrm{A}$, and, perhaps, derived conformational properties may be decisive.

\section{SYNTHETIC CHALLENGES AND BIOLOGICAL SYNTHETIC PATHWAY}

In addition to its appealing biological activity, the structure of agelastatin has also been attractive to the synthetic community. The general structural features can be summarized in terms of three 4-fold characteristics, thus:

(1) Four rings. All agelastatins contain an unusual 5-6-5-5 fused tetracylic ring system, including an A-ring bromopyrrole motif, a B-ring piperazinone, a C-ring cyclopentane, and a D-ring imidazolone (urea).

(2) Four stereocenters. Agelastatin contains four contiguous stereocenters, all of which are located on the five-membered C-ring.

(3) Four nitrogen atoms. Each of these stereogenic centers bears a nitrogen atom. Stereoselective introduction of a nitrogen functionality can be very challenging.

Besides agelastatin's unique structure, early semisynthetic efforts by Pietra have indicated some additional challenges and provided inspirations for the total synthesis [7]:

(1) The $\mathrm{C}(13)$ bromine atom can be simply cleaved in the presence of sodium hydride or LAH.

(2) The $\mathrm{C}(5)$ hydroxyl group can be eliminated by treatment of dry warm pyridine or Amberlyst 15 in $\mathrm{CHCl}_{3}$ to give imidazolones 8 (eq. 2).

(3) The C/D ring junction was found to have certain flexibility during an effort in hydrolyzing imidazolones 8 . The $\mathrm{C}(4), \mathrm{C}(5)$ epimers $(\mathbf{9})$ were observed in a mixture along with the natural isomers (7) (eq. 3).
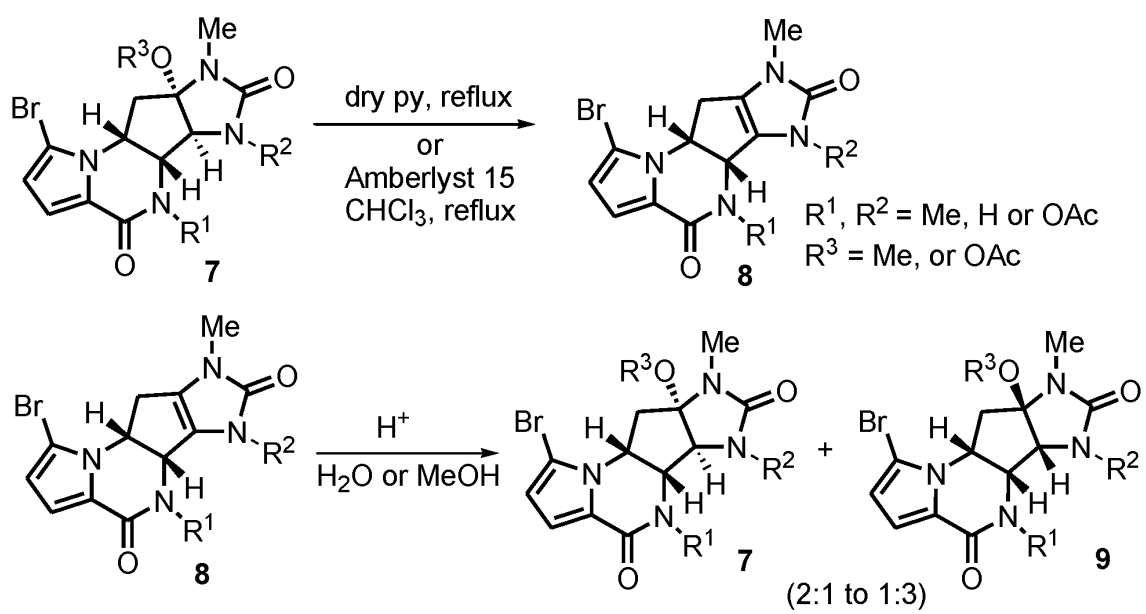
Two biosynthetic pathways have been suggested. Pietra proposed a cascade route starting from a hymenidin-like precursor 10 (Scheme 1A) [5]; while Mourabit prefers to begin with an oxidized hymenidine precursor (12) that can proceed through a cyclization to install the C-ring, which can undergo pyrrole-participated conjugated addition to provide the tetracycle skeleton (Scheme 1B) [14]. Note that Mourabit's proposal relies on multiple imine-enamine tautomerizations.

\section{(A) Pietra, 1993}

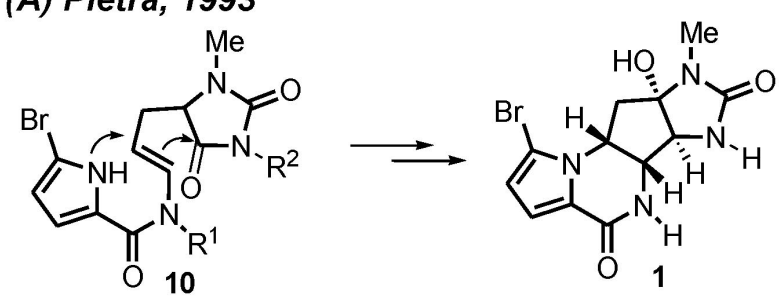

(B) Mourabit, 2001

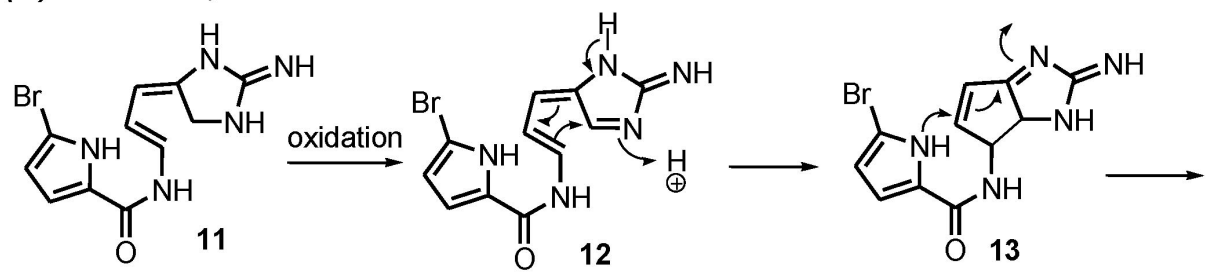

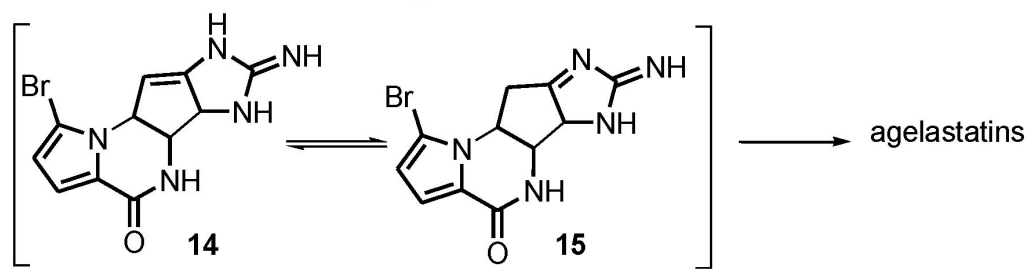

Scheme 1 Biosynthetic pathway.

\section{TOTAL SYNTHESES OF AGELASTATINS}

To date, 11 groups have completed the total synthesis of agelastatin and a variety of strategies have been employed. Given that the D-ring of agelastatin can be assembled by spontaneous cyclization from a ketone intermediate (eq. 4), focus will be given to the strategic design on the construction of the fused $\mathrm{ABC}$-ring tricycle.

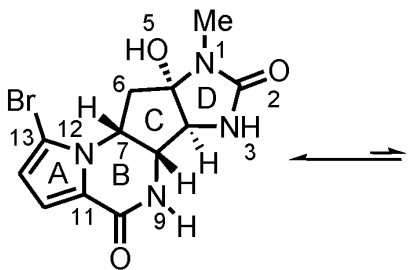

agelastatin $A(1)$

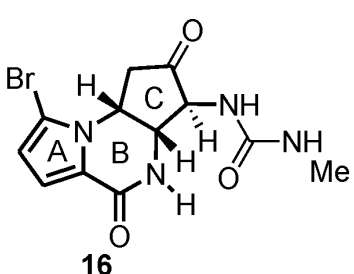

16 


\section{Weinreb's racemic synthesis of agelastatin A (1999)}

Weinreb's group accomplished the first total synthesis of racemic agelastatin A in 1999 [15]. Their strategy for the ABC-ring synthesis is illustrated in Scheme 2. The B-ring would be constructed in the end of the synthesis via participation of the pyrrole terminus of a bicyclic precursor in an intramolecular Michael addition. Disconnection at N(9)-C(10) bond reveals amide intermediate 18, which would be synthesized by acylation of a C-ring-containing compound (19).

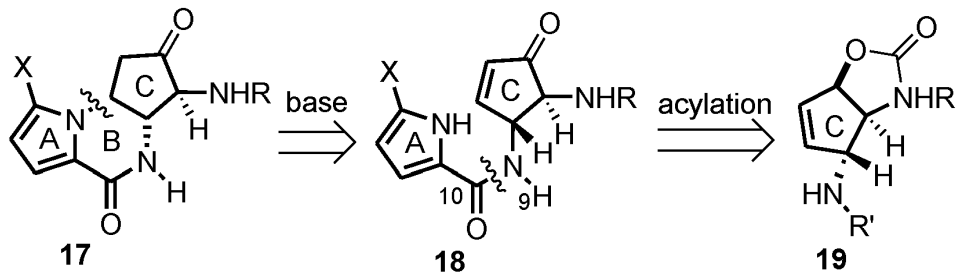

Scheme 2 Weinreb's assembly strategy.

In a forward sense, Weinreb's synthesis beautifully utilized pericyclic reactions multiple times to construct the polyfunctionalized C-ring (Scheme 3). It was first used in an $\mathrm{N}$-sulfinyl-mediated Diels-Alder reaction, second in a [2,3]-sigmatropic rearrangement to launch the $\mathrm{C}(5)-\mathrm{O}$ and $\mathrm{C}(4)-\mathrm{N}(3)$ bonds, and third in a Kresze-type ene reaction [16] to introduce the $\mathrm{C}(8)-\mathrm{N}(9)$ bond. With amine 19 in hand, acylation with 2-trimethylsilyl (TMS) pyrrole acyl chloride, followed by a chemoselective hydrolysis of cyclic carbamate and pyridinium dichromate (PDC) oxidation led to enone 18. Treatment of enone 18 with $\mathrm{Cs}_{2} \mathrm{CO}_{3}$ provided the ABC-ring tricycle (17). Note that the TMS group was purposely employed as a surrogate for the labile $\mathrm{C}(13)$ bromine atom. Weinreb's route has set a high-level benchmark for the total synthesis of agelastatin A, and this strategy, especially the use of 1,4-addition to assemble the B-ring core, has been employed by many following efforts.
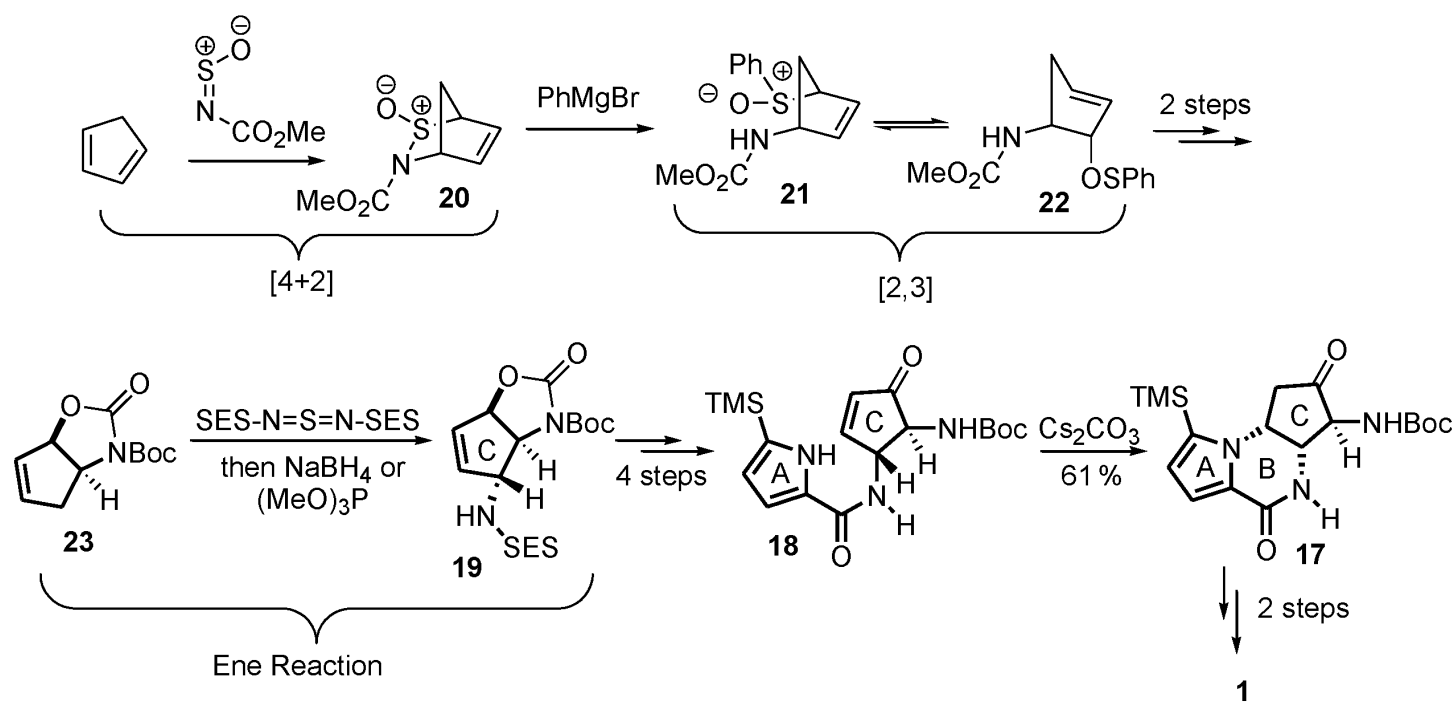

Scheme 3 Weinreb's racemic synthesis of agelastatin A. 


\section{Feldman's syntheses of (-)-agelastatins A and B (2002)}

The first enantioselective syntheses of (-)-agelastatins A and B were accomplished by Feldman's group in 2002 [17]. The general strategy for the ABC-ring assembly is illustrated in Scheme 4. Similar to Weinreb's strategy, the B-ring was constructed at the very end of the synthesis via an elegant one-pot alcohol oxidation-sulfone elimination-Michael addition sequence; the amide precursor $\mathbf{2 6}$ was ultimately derived from acylation of amide 27.

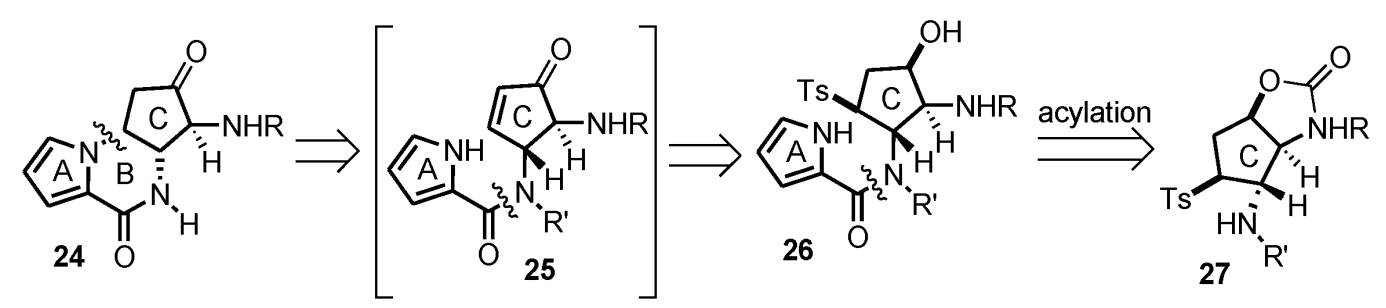

Scheme 4 Feldman's assembly strategy.

In a forward manner, Feldman's synthesis can be highlighted by two novel aspects: (1) utilization of alkynyliodonium salts and (2) multiple usage of sulfone functionality. Starting from chiral epoxide 28, alkynyliodonium salt 30 can be prepared by treatment of stannane 29 using Stang's reagent (Scheme 5) [18]. Upon nucleophilic addition of $p$-toluenesulfinate salt, the resulting alkylidene-carbene 31 underwent a diastereoselective $\mathrm{C}-\mathrm{H}$ insertion to give the agelastatin $\mathrm{C}$-ring along with some 1,2-migration product 33. Subsequently, vinyl sulfone serves as a Michael acceptor to allow installation of the $\mathrm{N}(9)$ group. After an acylation-hydrolysis process, treatment of alcohol 26 under Moffat-Swern

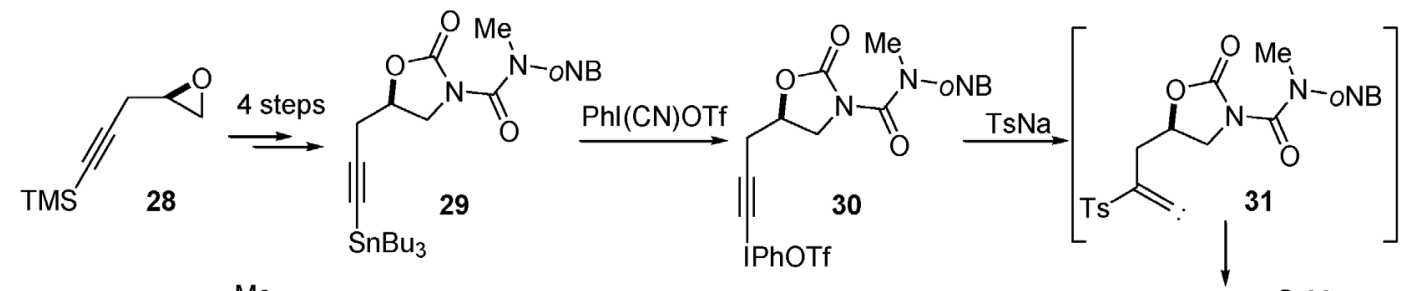

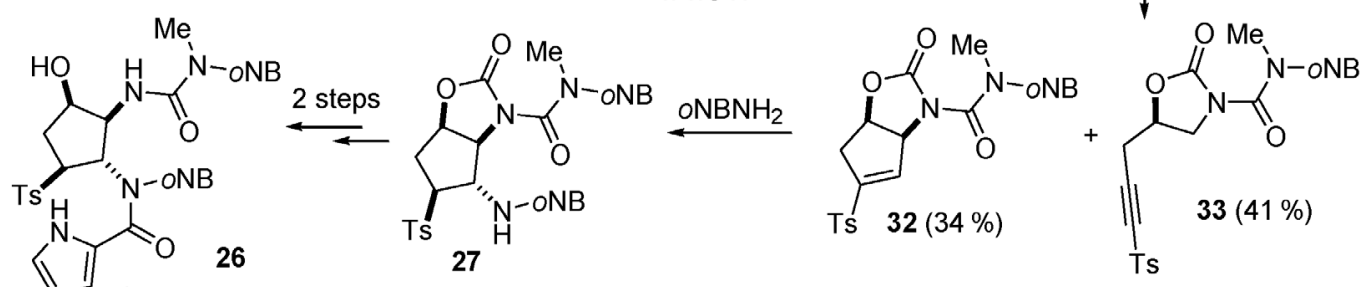

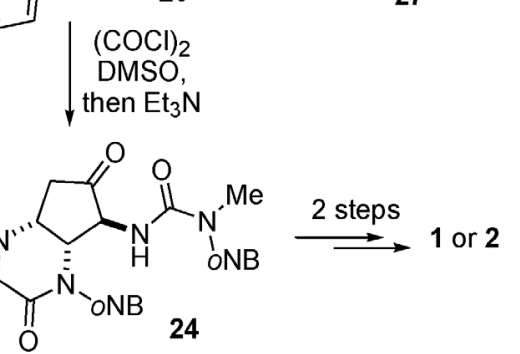

Scheme 5 Feldman's enantioselective syntheses of (-)-agelastatins A and B. 
oxidation conditions [19] furnished $\mathrm{ABC}$ tricycle 24, which can be transformed to either agelastatin A or B in two steps. Note that Feldman's synthesis represents the first synthesis of agelastatin B, and this late-stage bromination protocol has been adopted by many others.

\section{Hale's formal and total synthesis of (-)-agelastatin A (2003 and 2004)}

Hale and co-workers completed a formal total synthesis of (-)-agelastatin A in 2003 [20] along with a new total synthesis in 2004 [21]. Both syntheses utilized a similar strategy for the ABC-ring construction as the one in Weinreb's synthesis, but in an asymmetric fashion. Hale's route initiates with chiral aziridine 34 (Hough-Richardson aziridine), which can be prepared in 5 steps from a sugar derivative (Scheme 6). Upon a 10-step sequence, a ring-closing metathesis (RCM) was employed for the C-ring closure providing compound 36. Transformation of intermediate $\mathbf{3 6}$ to carbamate $\mathbf{3 7}$ followed by a 4-step elaboration afforded cyclization precursor 38. (-)-Agelastatin A was then achieved in 4 steps from 38. The RCM strategy employed in Hale's strategy has been utilized by many others in the agelastatin C-ring synthesis.

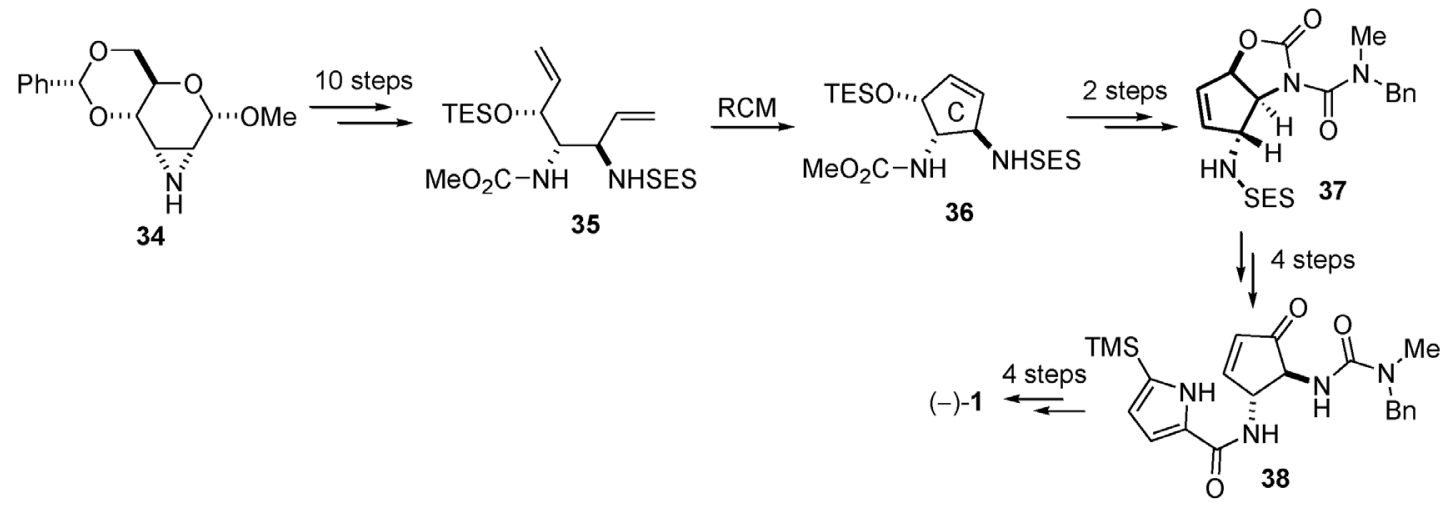

Scheme 6 Hale's asymmetric synthesis of agelastatin A.

\section{Davis's synthesis of (-)-agelastatin A (2005)}

A concise asymmetric synthesis of (-)-agelastatin A was developed by Davis's group in 2005 [22], and the yields of certain steps were improved in 2009 [23]. A similar 1,4-addition was employed for the B-ring closure to install the ABC-ring tricycle (Scheme 7). In Davis' strategy, the A-ring pyrrole was introduced first followed by formation of the C-ring through olefin metathesis. The RCM precursor would ultimately be synthesized from diamine $\mathbf{4 2}$.
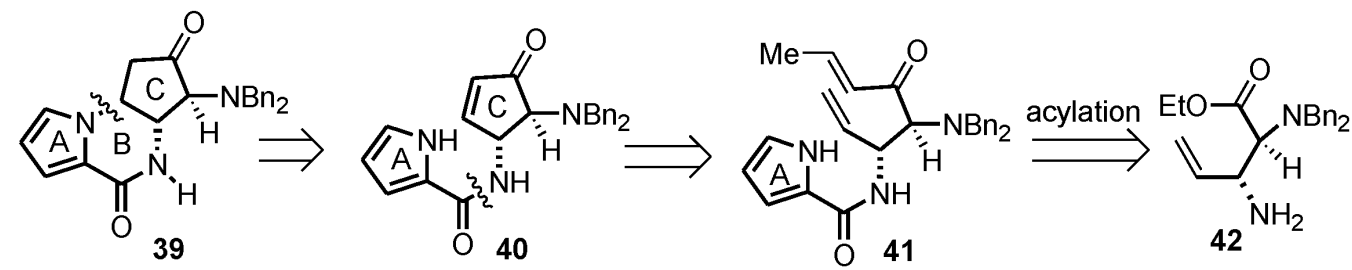

Scheme 7 Davis's assembly strategy. 
Davis' synthesis is featured by high efficiency in stereocontrol and functionality introduction. Utilizing acrolein-derived chiral sulfinimine $\mathbf{4 3}$, two nitrogen-containing stereocenters were beautifully introduced in one step, and the reactivity of the two nitrogens was differentiated by different protecting groups (Scheme 8). Upon acylation with pyrrole-2-carboxylic acid, diene $\mathbf{4 1}$ was obtained in just a few steps. The RCM reaction went uneventfully to furnish the C-ring affording the Michael addition precursor 40. A three-step elaboration (1,4-addition, deprotection-urea formation, and bromination) led to the final product (-)-agelastatin A.

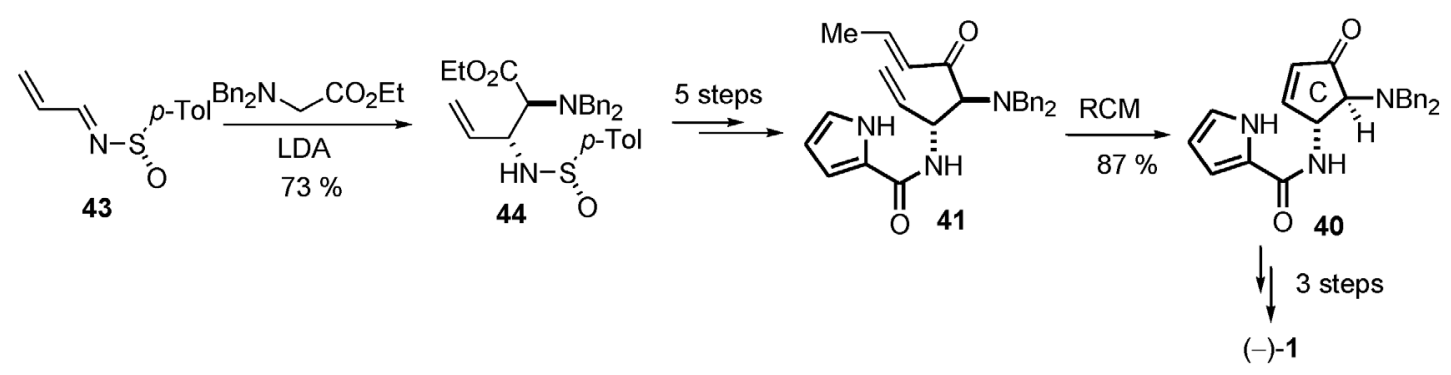

Scheme 8 Davis's synthesis: A chiral sulfinimine strategy.

\section{Du Bois's synthesis of (-)-agelastatin A (2006)}

An efficient route to (-)-agelastatin A was accomplished by Du Bois and Wehn in 2006 [24]. Their strategy for ring assembly is distinct from the previous ones (Scheme 9): the B-ring would be installed at a late stage via an amide formation; the A-ring pyrrole would be introduced from Paal-Knorr condensation from polyfunctionalized amine precursor 47 .
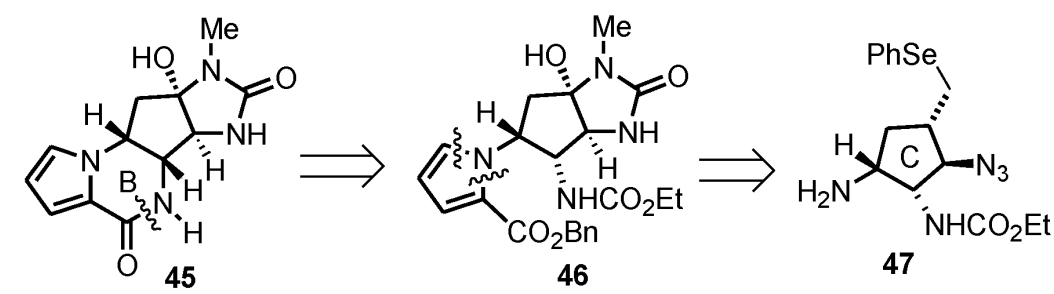

Scheme 9 Du Bois's assembly strategy.

The Du Bois group has extensively developed elegant methodology based on stereoselective Rh-catalyzed intramolecular aziridination reactions. The efficacy of this methodology has been nicely illustrated in this synthesis (Scheme 10). Chiral sulfamate $\mathbf{4 9}$ was prepared in high yield over three steps from lactam (-)-48. The $\mathrm{Rh}^{\mathrm{II}}$-catalyzed aziridination was achieved in excellent yield and diastereoselectivity with low catalyst loading. With a rigid tricycle $\mathbf{5 0}$ in hand, two functionalities can be sequentially introduced: first, the aziridine was selectively opened with azide at the internal position; second, a selenide attacked at the external $\mathrm{C}-\mathrm{O}$ bond after an $\mathrm{N}$-acylation. Such a sequence beautifully set up all the required stereocenters providing amine 47. Paal-Knorr condensation was then employed for the A-ring synthesis to afford pyrrole 52. A three-step sequence was next used to furnish the D-ring urea (46). Treatment of intermediate $\mathbf{4 6}$ under basic conditions followed by bromination ultimately led to (-)-agelastatin A. 


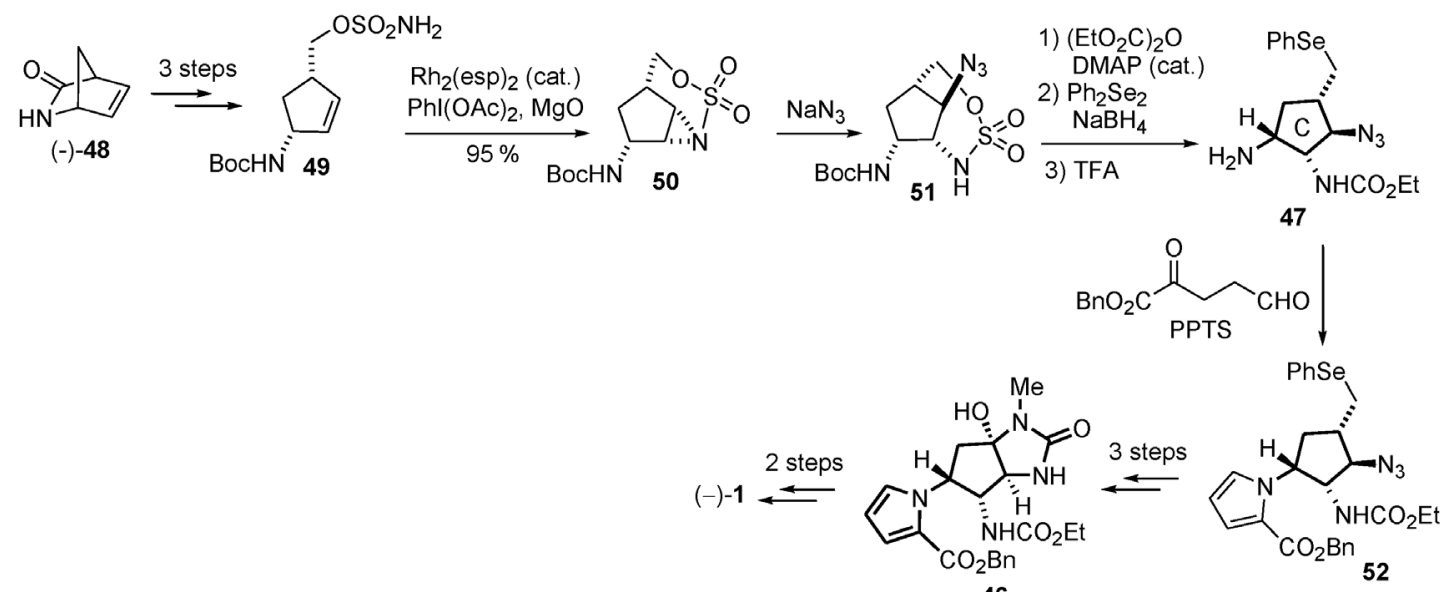

46

Scheme 10 Du Bois's synthesis: A Rh-catalyzed aziridine route.

\section{Trost's stereodivergent synthesis of both (+)- and (-)-agelastatin A (2006)}

In 2006, Trost and Dong developed a stereodivergent strategy to access both enantiomers of agelastatin A $[24,25]$. Aiming to provide a general access to various nitrogen-containing natural products, a new class of nucleophiles, pyrroles, and $\mathrm{N}$-alkoxyamides (hydroxamic esters) is developed for the Pd-catalyzed asymmetric allylic alkylation (AAA) reactions. These new tools allow rapid construction of agelastatin tricycle core with excellent chemo-, diastereo-, and enantioselective control (Scheme 11). For the synthesis of (+)-agelastatin A, amino-ketone $\mathbf{5 3}$ could be derived via olefin functionalization from tricycle 54. Piperazinone 54 would be accessed via a stepwise allylic alkylation: first introduction of the pyrrole $\mathrm{N}-\mathrm{C}$ bond and then the amide $\mathrm{N}-\mathrm{C}$ bond. For the synthesis of (-)-agelastatin A, tricycle 56 would be envisioned as the precursor to provide ent-53. A one-pot cascade reaction was designed between bis-electrophile $\mathbf{5 8}$ and bis-nucleophile $\mathbf{5 9 b}$ to generate the ABC-ring tricycle in just one step. A unique aspect of Trost's strategy is represented by the capability to access either tricyclic piperazinone regioisomer (54 or $\mathbf{5 6}$ ) from similar starting materials.

$(+) 1$<smiles>[R]N[C@H]1C(=O)C[C@H]2[C@H]1N(OC)C(=O)c1ccc(Br)n12</smiles>

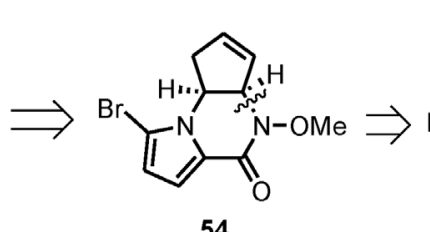

54

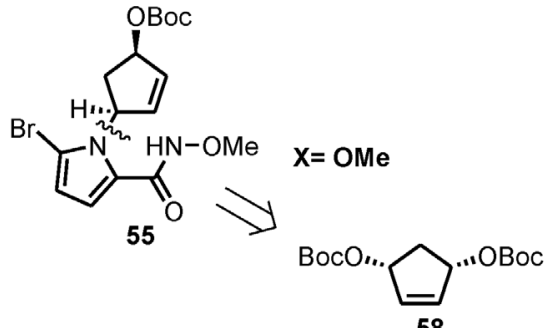

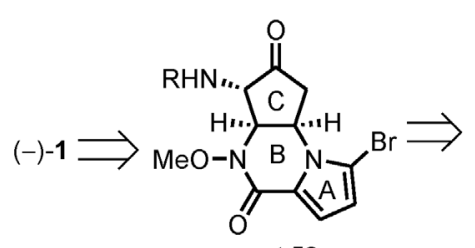
ent-53

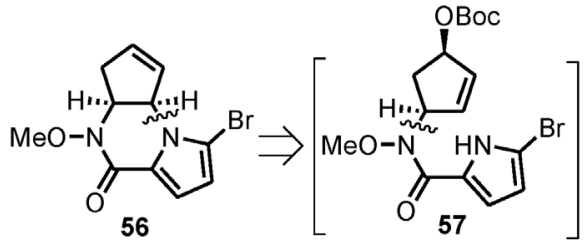<smiles>CC=C[V]#N</smiles><smiles>[X]C(=O)c1ccc(Br)[nH]1</smiles>

$59 \mathrm{a} X=\mathrm{OMe}$ $59 \mathrm{~b}$ X=NHOMe

Scheme 11 Trost's assembly strategy. 
In a forward fashion, the Pd-catalyzed AAA between pyrrole 59a and carbonate $\mathbf{5 8}$ provided adduct 60 in good yield and high enantioselectivity (Scheme 12). $(R, R)-\mathrm{L}_{\mathrm{ST}}$ (standard Trost ligand) was employed as the asymmetric ligand for Pd catalyst. After elaboration of the methyl ester to methoxyamide, a second Pd-catalyzed alkylation led to a high-yielding cyclization to tricycle piperazinone 54. Transformation of the olefin to the requisite amino-ketone was effected by two new catalytic systems: an NHC-copper-catalyzed aziridination and an $\mathrm{In}^{\mathrm{III}}$-catalyzed regioselective oxidative opening of an aziridine with dimethyl sulfoxide (DMSO). The $\mathrm{N}$-heterocyclic carbene (NHC)-Cu complex later proved to be an effective and general catalyst for aziridination of electron-deficient olefins [26]. The (+)-agelastatin A was ultimately completed by acylation of $\mathbf{5 3}$ with methyl isocyanate followed by reductive cleavage of $\mathrm{N}$-OMe and $\mathrm{N}$-Ts groups.

(A) Synthesis of (+)-agelastatin

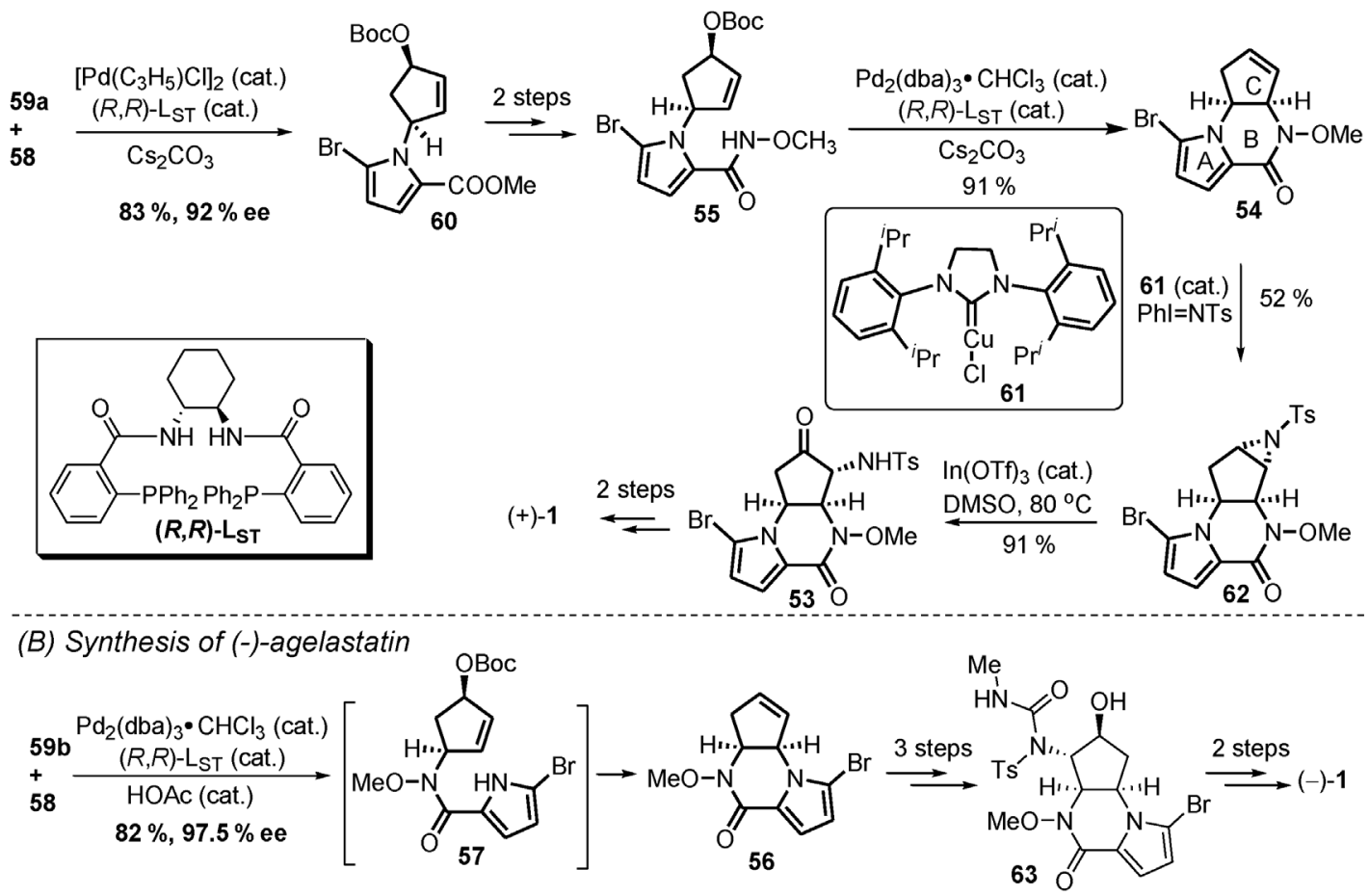

Scheme 12 Trost's stereodivergent synthesis of both product enantiomers of agelastatin A.

A concise synthesis of the (-)-agelastatin A has been achieved. Employment of nucleophile 59b containing both pyrrole and methoxyamide resulted in a one-pot double allylic alkylation. Piperazinone tricycle 56 was obtained in $83 \%$ yield and $97.5 \%$ ee, which indicated that the methoxyamide serves as a stronger nucleophile than the pyrrole under these conditions. The same chiral ligand $(R, R)-\mathrm{L}_{\mathrm{ST}}$ was utilized again for the enantioselective control, and use of acetic acid as a catalytic additive proved to be crucial. Introduction of the N(3) group was achieved by an allylic amination (Kresze reaction [16]); subsequent acylation followed by formal hydration of the olefin resulted in urea $\mathbf{6 3}$, which was elaborated to (-)-agelastatin A in two steps.

Some distinctive features are noteworthy in Trost's synthesis: (1) it represents the only agelastatin synthesis to date that utilizes a chiral catalyst to control the absolute stereochemistry; (2) it utilizes the same enantiomer of a stereoinducing catalyst to obtain either enantiomer of agelastatin A, and the two complementary routes differ only in the choice of nucleophile in the Pd AAA reactions; (3) it is the first 
agelastatin synthesis that introduces C(13) bromine atom at an early stage of the synthesis; (4) this synthesis necessitated development of new catalytic systems, but these also offer scope for general and widespread application.

\section{Ichikawa's synthesis of (-)-agelastatin A (2007)}

Ichikawa's group reported an asymmetric synthesis of agelastatin A in 2007 (Scheme 13) [27]. Similar to Weinreb and Hale's syntheses, this one also employed an intramolecular Michael addition to install the B-ring and an acylation for connection of A,C-rings (see Scheme 2). Ichikawa's synthesis is featured by a double usage of a [3,3]-sigmatropic rearrangement of allyl cyanate, which proves to be an effective strategy for [1,3]-chirality transfer and oxygen/nitrogen exchange. Starting from L-arabitol, two of the chiral $\mathrm{C}-\mathrm{O}$ bonds can be sequentially replaced with $\mathrm{C}-\mathrm{N}$ bonds. Carbamate $\mathbf{6 4}$ was next transformed to its corresponding allyl cyanate $\mathbf{6 5}$, which can undergo subsequent [3,3]-sigmatropic rearrangement to give more stable isocyanate 66. Elaboration of 66 to diol 67 set the stage for an RCM to generate the C-ring of agelastatin. Transformation of diol 68 to carbamate 69 required additional four steps. The same cyanate formation and [3,3]-rearrangement can be applied again to give protected amine 70. Further elaboration resulted in cyclopentenone Michael-precursor 71, which was ultimately converted to (-)-1 in four steps.

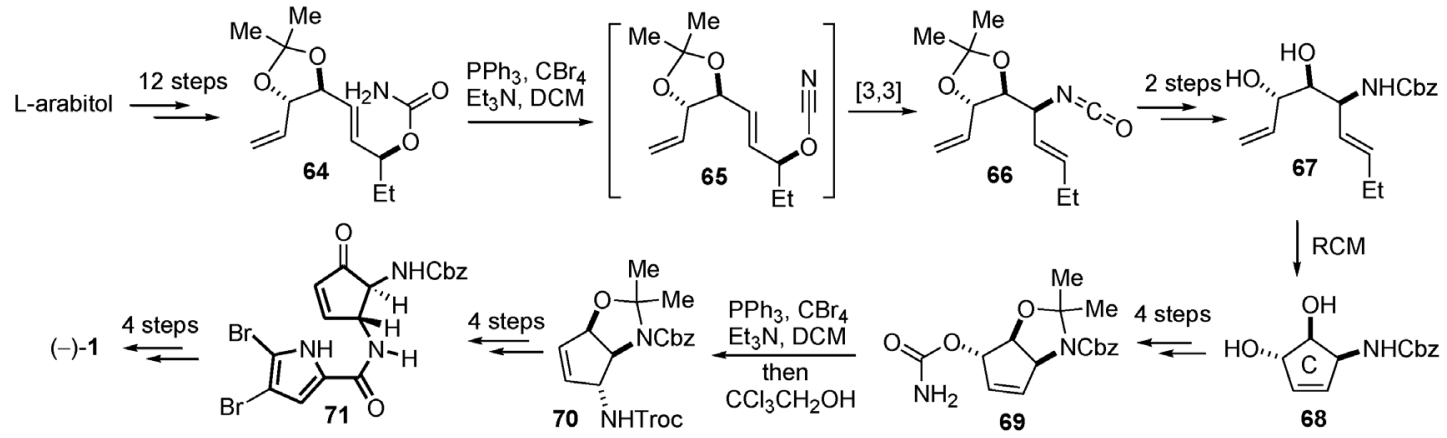

Scheme 13 Ichikawa's synthesis of (-)-agelastatin A.

\section{Yoshimitsu-Tanaka's synthesis of (-)-agelastatin A (2008 and 2009)}

The Yoshimitsu-Tanaka group accomplished a total synthesis of (-)-agelastatin A in 2008 [28] and an improved approach in 2009 [29]. Their strategy for the ABC-ring construction has some common aspects with Du Bois's route (Scheme 14): (1) the B-ring was formed at the end of the synthesis; (2) the $\mathrm{N}(3)$ and $\mathrm{N}(9)$ functionalities were introduced via an intramolecular aziridination reaction; (3) the A-ring pyrrole was assembled via Paal-Knorr condensation.

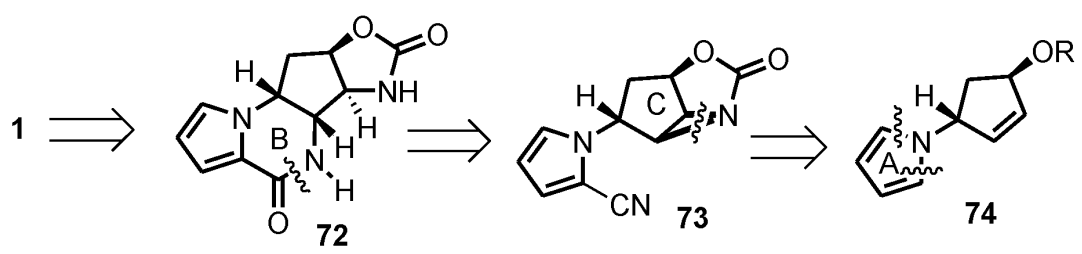

Scheme 14 Yoshimitsu-Tanaka’s assembly strategy. 
In a forward manner, chiral Boc-protected amine $\mathbf{7 5}$ was prepared in six steps from cyclopentadiene. The pyrrole A-ring was installed after removal of the Boc group (Scheme 15). A C1 unit was introduced by treatment of pyrrole $\mathbf{7 4}$ with trichloroacetyl isocyanate. Three steps were taken to transform the amide group to a nitrile and introduce the azidoformate group. Heating compound 77 at $160{ }^{\circ} \mathrm{C}$ under high pressure provided the desired aziridine $\mathbf{7 3}$ in $92 \%$ yield, which then underwent ring-opening by an azide to give compound 73. A three-step elaboration led to formation of the agelastatin B-ring. The resulting tetracyclic intermediate $\mathbf{7 2}$ was converted to the natural product in another three steps.

\section{First Generation:}

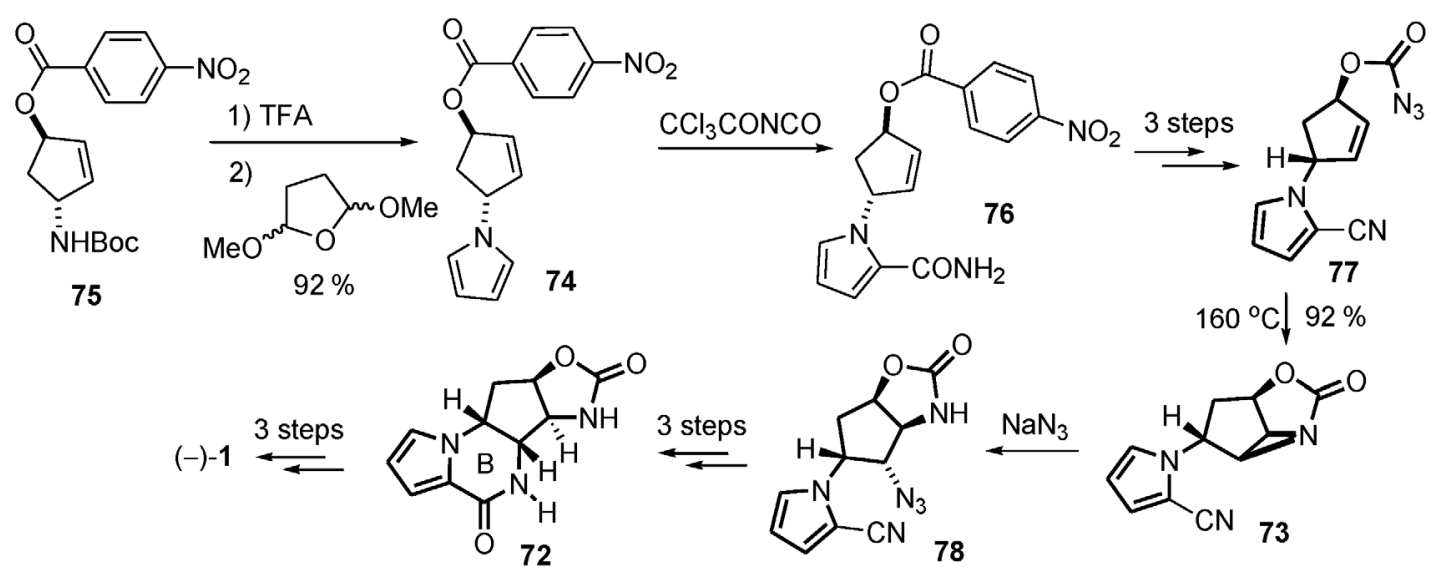

\section{Second Generation:}

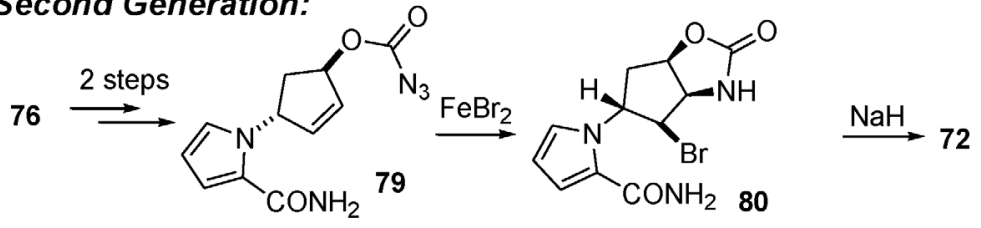

Scheme 15 Yoshimitsu-Tanaka's two-generation synthesis of (-)-agelastatin A.

In 2009, a second-generation strategy was developed to enhance the efficiency of the transformation of amide $\mathbf{7 6}$ to tetracycle $\mathbf{7 2}$, in which four steps are saved. An Fe ${ }^{\mathrm{II}}$-mediated radical cyclization, a method developed by Bach in 2000, was employed as the key step to offer bromo amide 80 [30]. Subsequent treatment of amide $\mathbf{8 0}$ with $\mathrm{NaH}$ provided lactam 72, which serves as the common intermediate in their previous route.

\section{Wardrop's synthesis of racemic agelastatin A (2009)}

In 2009, the Wardrop group developed an elegant synthesis of racemic agelastatin A [31]. Their synthesis is featured by multiple usage of a trichloroacetamide group: first as a substrate of Overman rearrangement to install the $\mathrm{N}(3)$ group (Scheme 16, 80); second as a nucleophile in the 5-exo-trig cyclofunctionalization for later introduction of the $\mathrm{N}(9)$ group; third as an amine protecting group; fourth as a urea surrogate, such as in compound $\mathbf{8 3}$. A four-step elaboration of urea $\mathbf{8 3}$ resulted in enone $\mathbf{8 4}$, which then functioned as a precursor for an intramolecular Michael addition. Subsequent debenzylation and bromination afforded racemic agelastatin $\mathrm{A}$. 


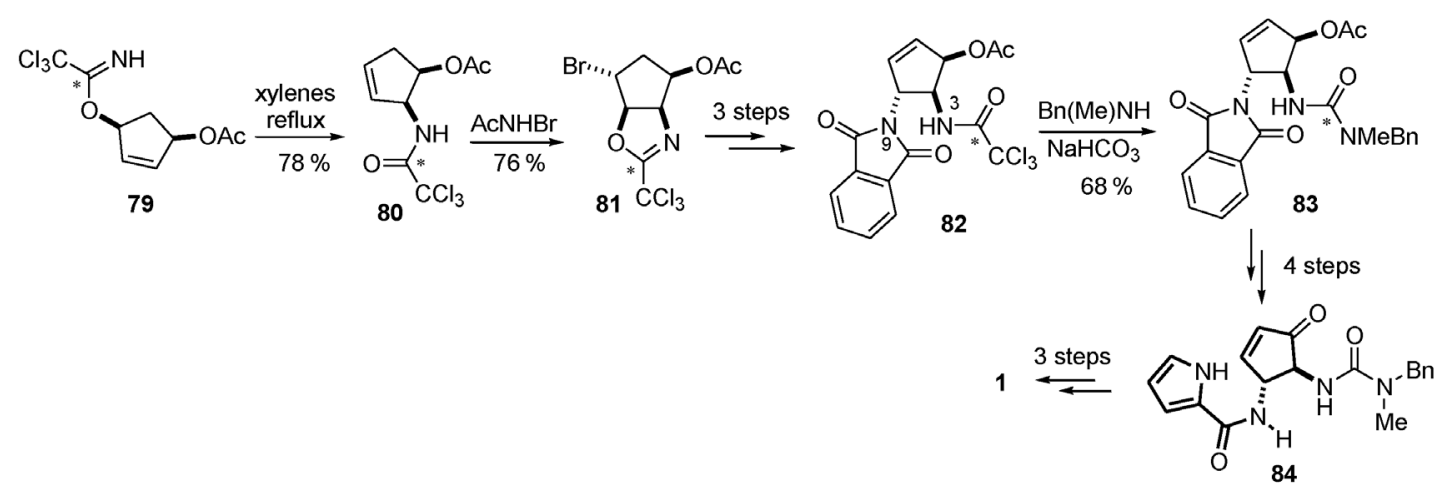

Scheme 16 Wardrop's synthesis: A trichloroacetamide strategy.

\section{Chida's synthesis of (-)-agelastatin A (2009)}

In 2009, another asymmetric synthesis of (-)-agelastatin A was reported by Chida and co-workers [32]. Similar to the strategies of Weinreb, Feldman, Hale, Ichikawa, and Wardrop, this synthesis also focuses on a de novo synthesis of the polysubstituted C-ring core. Chida's route is highlighted by multiple tandem sigmatropic rearrangements. Starting from commercially available chiral acetonide $\mathbf{8 5}$, diene 86 was prepared in seven steps (Scheme 17). Treatment of diene 86 with a base at $140{ }^{\circ} \mathrm{C}$ led to two tandem stereoselective Overman rearrangements, providing vicinal diamine 88. Oxidation of the sulfide to allylic sulfoxide resulted in a subsequent [2,3]-sigmatropic rearrangement, and product $\mathbf{8 9}$ is structurally analogous to Hale's intermediate 35. An RCM strategy was then used to introduce the C-ring followed by a cyclization to give oxazoline 90. A seven-step sequence was next employed to prepare the Michael addition precursor 91. Treatment of enone 91 with a base followed by debenzylation provided (-)-agelastatin A.

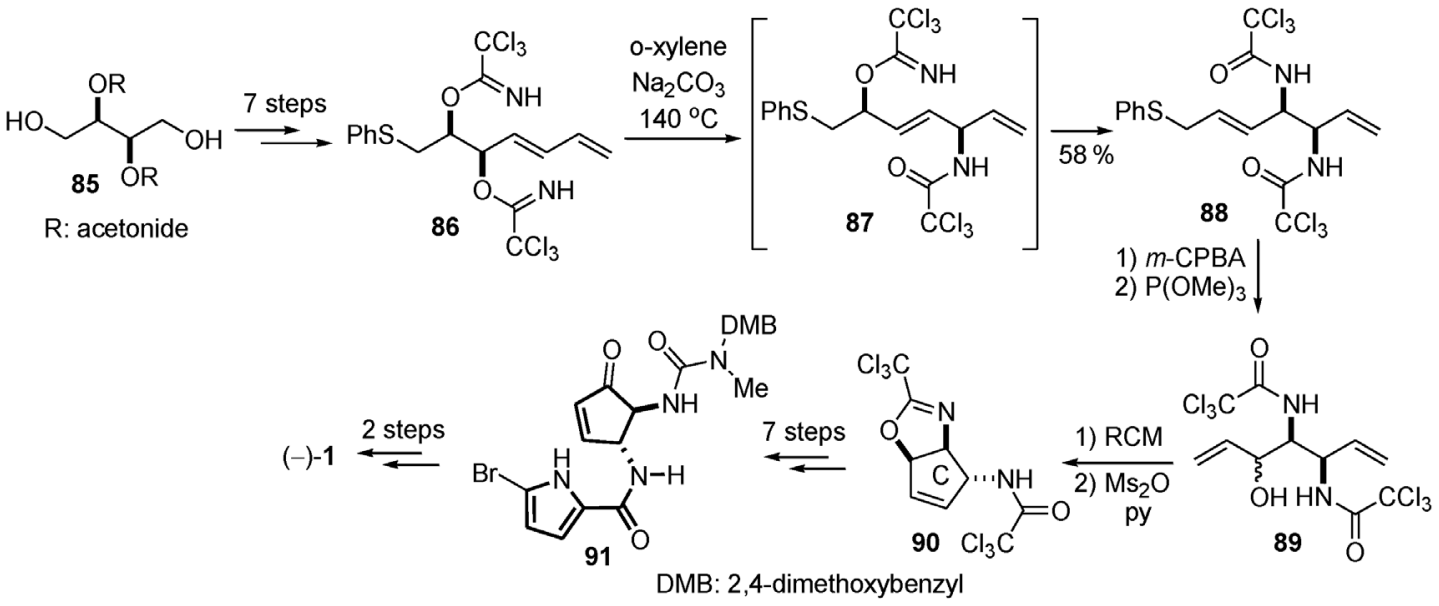

Scheme 17 Chida's synthesis: A strategy with tandem sigmatropic rearrangements. 


\section{Movassaghi's synthesis of (-)-agelastatins A-F (2010)}

The most recent work comes from Movassaghi's group, in which a highly concise synthesis of (-)-agelastatins A-F was accomplished [10]. Movassaghi's strategy was initially inspired by the biosynthesis of these natural products, and a clever route was adopted (Scheme 18). Unlike previous syntheses, they decided to construct the $\mathrm{C}$-ring at the very end of the synthesis via a 5-exo-trig cyclization; the intermediate 92 would come from hemiaminal 93. The D-ring imidazolone would be derived from an ester group; cleavage of the $\mathrm{C}(8)-\mathrm{N}(9)$ bond disclosed that the B-ring would be formed from bisester $\mathbf{9 5}$.

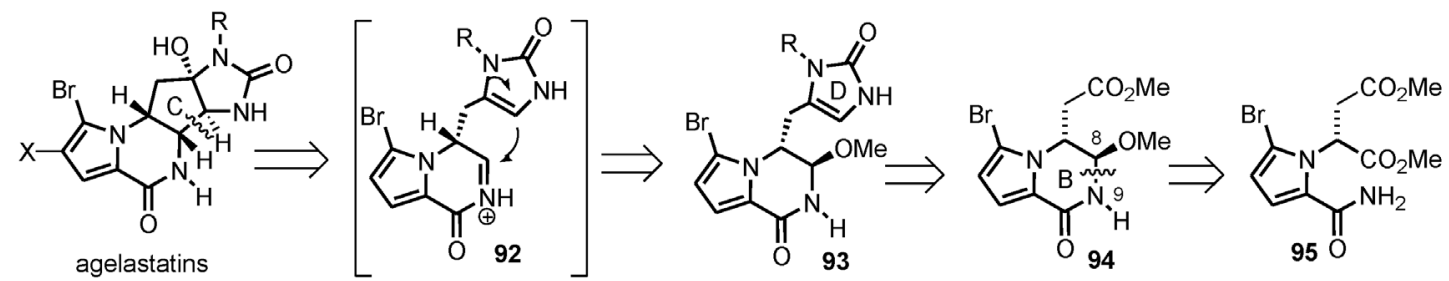

Scheme 18 Movassaghi's assembly strategy.

In a forward manner, chiral amide $\mathbf{9 5}$ could be prepared in three straightforward steps from D-aspartic acid dimethylester (96). Treatment of amide 95 with $\mathrm{NaBH}_{4}$ in $\mathrm{MeOH}$ followed by addition of $\mathrm{TsOH}$ in $\mathrm{MeOH}$ resulted in a tandem lactam formation/imide reduction. Three transformations are required to convert the methyl ester to the requisite imidazolone: (1) formation of a thioester; (2) a $\mathrm{Cu}$-mediated ketone synthesis using ureastannane 99 as the nucleophile; (3) dehydration with $\mathrm{HCl}$ in $\mathrm{MeOH}$. The resulting imidazolones 93a and 93b serve as key intermediates for agelastatin synthesis. Remarkably, reaction of 93a with a strong Brønsted acid in water afforded (-)-agelastatin A (1) in $47 \%$ yield, along with C3,C4 epimer 97 (24\% yield). (-)-Agelastatin B (2) can be readily derived from $\mathbf{1}$ in $84 \%$ yield. Heating epimer $\mathbf{9 7}$ in dry pyridine led to nearly quantitative conversion to imidazolone $\mathbf{8}$, an intermediate that has been observed in Pietra's semisynthesis [7]. Oxidation of the tetrasubstituted olefin with dimethyldioxirane (DMDO) gave the C3,C4-epi-agelastatin C (98), which can undergo an acid-mediated equilibration to provide (-)-agelastatin C (3) in $41 \%$ yield.

In a similar fashion, (-)-agelastatin D (4) was prepared from imidazolone 93b albeit in $26 \%$ yield, and bromination of $\mathbf{4}$ uneventfully gave (-)-agelastatin $\mathrm{F}(\mathbf{6})$ in $86 \%$ yield. Adopting a known procedure [6], conversion of (-)-agelastatin E (5) from 1 was secured in $96 \%$ yield. Therefore, Movassaghi's synthesis provides a unified route for access of all the known agelastatin alkaloids (Scheme 19). Several unique features are noteworthy:

(1) Practicality. This synthesis represents one of the most concise syntheses of $\mathbf{1}$ with high yielding and scalability (gram-scale preparation).

(2) Structure confirmation. For the first time, structures of $\mathbf{2}$ and $\mathbf{4}$ were confirmed by X-ray crystallography, and structures of $\mathbf{3}$ and $\mathbf{6}$ were confirmed by total synthesis.

(3) Inspiration. Movassaghi's synthesis provides an important implication to the biosynthesis of the agelastatin family, especially on the pivotal role of the $\mathrm{C}(13)$ bromine atom. 


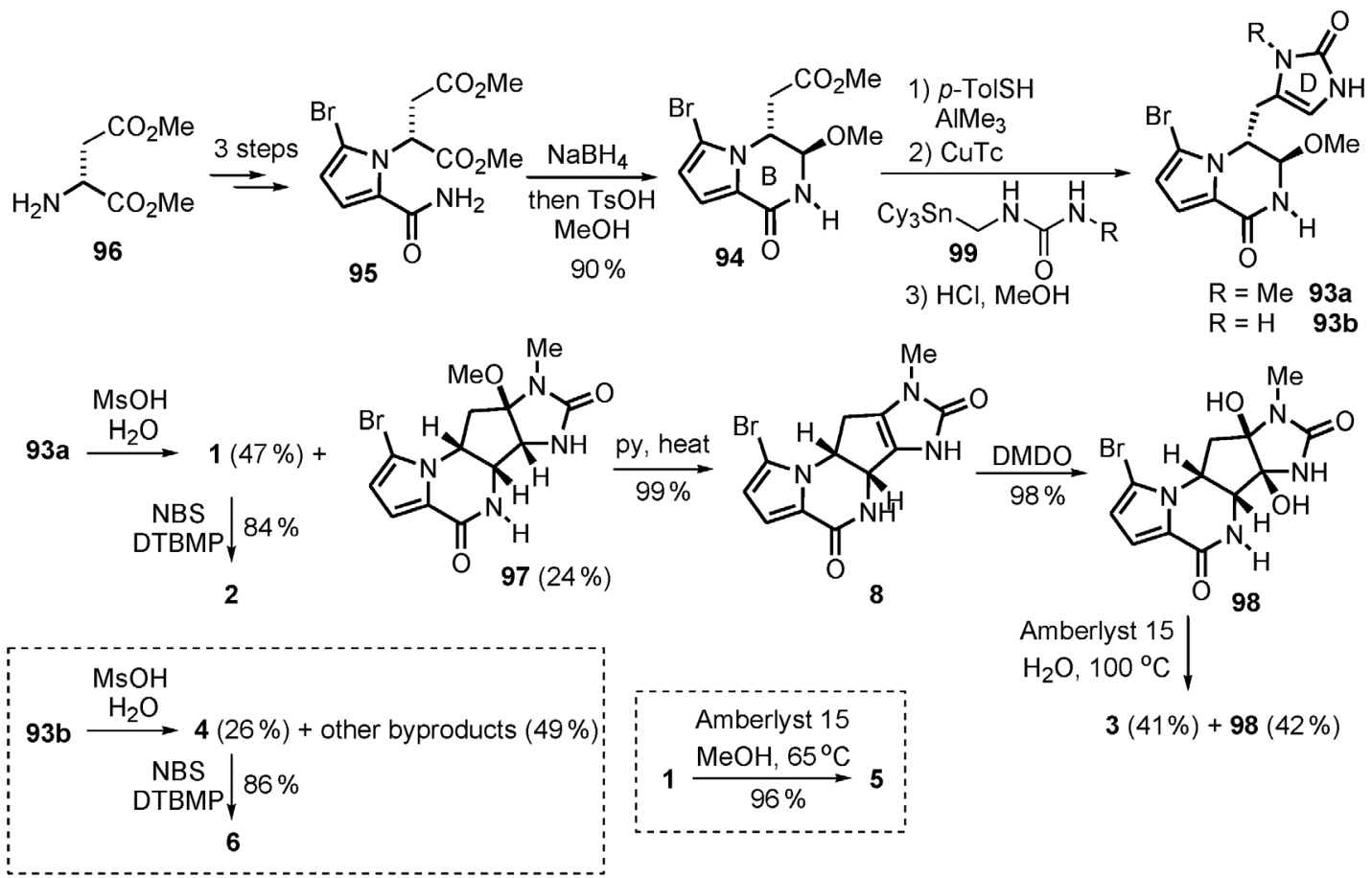

Scheme 19 Movassaghi's synthesis: A biomimetic strategy.

\section{CONCLUSION}

This review highlights recent efforts toward the total synthesis of agelastatin A, a highly potent anticancer agent, and other agelastatins. To date, 11 research groups have accomplished elegant syntheses of this marine alkaloid; and during these syntheses, various new methods and graceful strategies have been developed. These methods and strategies have provided valuable lessons not only for the production of agelastatins, but also for the synthesis of numerous other related alkaloid natural products.

\section{ACKNOWLEDGMENTS}

I thank IUPAC for providing the opportunity to present this work; I also thank my Ph.D. mentor Prof. Barry M. Trost for his invaluable advice, guidance, and encouragement over the years. I thank Prof. Du Bois for helpful discussion and Prof. Movassaghi for sharing advanced information on their work. I thank the Stanford Graduate Fellowship and the Camille and Henry Dreyfus Environmental Chemistry Fellowship for funding.

\section{REFERENCES}

1. Z. Jin. Nat. Prod. Rep. 23, 464 (2006) and refs. therein.

2. S. M. Weinreb. Nat. Prod. Rep. 24, 931 (2007).

3. (a) C. K. Mason, S. McFarlane, P. G. Johnston, P. Crowe, P. J. Erwin, M. M. Domostoj, F. C. Campbell, S. Manaviazar, K. J. Hale, M. El-Tanani. Mol. Cancer Ther. 7, 548 (2008); (b) K. J. Hale, M. M. Domostoj, M. El-Tanani, F. C. Campbell, C. K. Mason. In Strategies and Tactics in Organic Synthesis, M. Harmata (Ed.), p. 352, Academic Press, London (2005). 
4. S. Tilvi, C. Moriou, M. Martin, J. Gallard, J. Sorres, K. Patel, S. Petek, C. Debitus, L. Ermolenko, A. Al-Mourabit. J. Nat. Prod. 73, 720 (2010).

5. M. D’Ambrosio, A. Guerriero, C. Debitus, O. Ribes, J. Pusset, S. Leroy, F. Pietra. Chem. Commun. 1305 (1993).

6. M. D'Ambrosio, A. Guerriero, G. Chiasera, F. Pietra. Helv. Chim. Acta 77, 1895 (1994).

7. M. D'Ambrosio, A. Guerriero, M. Ripamonti, C. Debitus, J. Waikedre, F. Pietra. Helv. Chim. Acta 79, 727 (1996).

8. G. R. Pettit, S. Ducki, D. L. Herald, D. L. Doubek, J. M. Schmidt, J. C. Chapuis. Oncol. Res. 15, 11 (2005).

9. T. W. Hong, D. R. Jímenez, T. F. Molinski. J. Nat. Prod. 61, 158 (1998).

10. M. Movassaghi, D. S. Siegel, S. Han. Chem. Sci. (2010). doi:10.1039/C0SC00351D

11. L. Meijer, A. M. Thunnissen, A. W. White, M. Garnier, M. Nikolic, L. H. Tsai, J. Walter, K. E. Cleverley, P. C. Salinas, Y. Z. Wu, J. Biernat, E. M. Mandelkov, S. H. Kim, G. R. Pettit. Chem. Biol. 7, 51 (2000).

12. C. K. Mason, S. McFarlane, P. G. Johnston, P. Crowe, P. J. Erwin, M. M. Domostoj, F. C. Campbell, S. Manaviazar, K. J. Hale, M. El-Tanai. Mol. Cancer Ther. 7, 548 (2008).

13. K. J. Hale, M. M. Domostoj, D. A. Tocher, E. Irving, F. Scheinmann. Org. Lett. 5, 2927 (2003).

14. A. Al Mourabit, P. Potier. Eur. J. Org. Chem. 237 (2001).

15. D. Stien, G. T. Anderson, C. E. Chase, Y. Koh, S. M. Weinreb. J. Am. Chem. Soc. 121, 9574 (1999).

16. R. Bussas, G. Kresze. Liebigs Ann. Chem. 629 (1980).

17. (a) K. S. Feldman, J. C. Saunders. J. Am. Chem. Soc. 124, 9060 (2002); (b) K. S. Feldman, J. C. Saunders, M. L. Wrobleski. J. Org. Chem. 67, 7096 (2002).

18. P. J. Stang, V. V. Zhdankin. J. Am. Chem. Soc. 113, 4571 (1991).

19. For a review, see: T. T. Tidwell. Synthesis 857 (1990).

20. K. J. Hale, M. M. Domostoj, D. A. Tocher, E. Irving, F. Scheinmann. Org. Lett. 5, 2927 (2003).

21. M. M. Domostoj, E. Irving, F. Scheinmann, K. J. Hale. Org. Lett. 6, 2615 (2004).

22. F. A. Davis, J. Deng. Org. Lett. 7, 621 (2005).

23. F. A. Davis, Y. Zhang, H. Qiu. Synth. Commun. 39, 1914 (2009).

24. (a) P. M. Wehn. Ph.D. Thesis, Stanford University (2006); (b) P. M. Wehn, J. Du Bois. Angew. Chem., Int. Ed. 48, 3802 (2009).

24. B. M. Trost, G. Dong J. Am. Chem. Soc. 128, 6054 (2006).

25. B. M. Trost, G. Dong. Chem.-Eur. J. 15, 6910 (2009).

26. Q. Xu, D. H. Appella. Org. Lett. 10, 1497 (2008).

27. Y. Ichikawa, T. Yamaoka, K. Nakano, H. Kotsuki. Org. Lett. 9, 2989 (2007).

28. T. Yoshimitsu, T. Ino, T. Tanaka. Org. Lett. 10, 5457 (2008).

29. T. Yoshimitsu, T. Ino, N. Futamura, T. Kamon, T. Tanaka. Org. Lett. 11, 3402 (2009).

30. T. Bach, B. Schlummer, K. Harms. Chem. Commun. 287 (2000).

31. D. P. Dickson, D. J. Wardrop. Org. Lett. 11, 1341 (2009).

32. N. Hama, T. Matsuda, T. Sato, N. Chida. Org. Lett. 11, 2687 (2009). 